\title{
AUTOMATIC TOLL COLLECTION USING OPTICAL CODE RECOGNITION AND ENCRYPTION
}

\author{
Nikita More $^{1}$, Sayli Ghadi ${ }^{2}$, Vishwesh Satapute ${ }^{3}$, Swapnil Gharat ${ }^{4}$

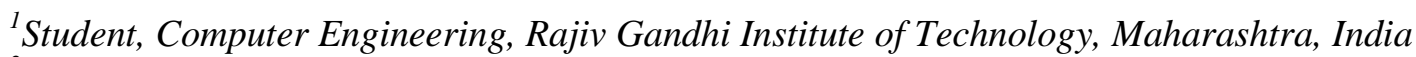 \\ ${ }^{2}$ Student, Computer Engineering, Rajiv Gandhi Institute of Technology, Maharashtra, India \\ ${ }^{3}$ Student, Computer Engineering, Rajiv Gandhi Institute of Technology, Maharashtra, India \\ ${ }^{4}$ Assistant Professor, Computer Engineering, Rajiv Gandhi Institute of Technology, Maharashtra, India
}

\begin{abstract}
Automatic Toll Collection Using Optical Code Recognition and Encryption provides an alternative to the current existing toll collections techniques and tries to overcome the drawbacks of these system. In this system, the number plate of a particular vehicle is encrypted using DES algorithm and an OCR code is generated out of it. This code is used as sticker on the car windshield. High Definition (HD) cameras capture this code and image processing is performed using Open CV functions on the code. It is then matched in the database. If matched, the tax is debited from the users account and the vehicle is allowed to pass within seconds. If the balance is insufficient then only once pass is allowed. After that the payment has to be made manually. An additional feature that supports this system is that if a vehicle is stolen and an entry is being made in the central database for the same by the police then if the vehicle passes through the toll plaza, a silent alarm would buzz. which would indicate the operator at the toll booth that the vehicle is a stolen vehicle.
\end{abstract}

Keywords: Open CV, OCR, Encryption, Image Processing, DES Algorithm

\section{INTRODUCTION}

Automation being the need of today has made tremendous advancement in all most all areas. One of which is Automatic toll collection which is rapidly becoming a globally accepted toll collection system. Initial toll collection being manual in nature and time consuming, thereby leads to traffic congestion, pollution and a lot of frustration. Quite obviously, this process makes it necessary for the manual services to be rendered continuously through the day and night. Ever increasing need for efficient, reliable, safe, and cheap toll taxation along with image processing resulted in the development of different kinds of solutions. Automatic Toll Collection System using Optical Code Recognition and Encryption aims at successfully removing unnecessary traffic delays, faster and reliable processing, keeping an eye on unauthorized vehicles, etc.

In this paper we present a model based on image processing which can be employed for real time automatic vehicle toll collection system. A High Definition (HD) camera is used to capture an OCR code of an incoming vehicle's windshield. This is followed by the process of feature extraction wherein a particular feature, say the OCR code on the windshield is extracted using suitable techniques. Verification is done and deduction process is carried out thereby allowing the vehicles to pass.

\section{EXISTING SYSTEM}

The concept of automatic toll collection has been studied since 1992 and is based on the RFID Tags. The research paper titled "ELECTRONIC TOLL COLLECTION
SYSTEM USING PASSIVE RFID TECHNOLOGY" [1] gives the overview of the toll collection system using RFID. The concept is based on existing toll booths; however human intervention is no longer required. The vehicles will be given a passive tag in the form of a sticker which could be affixed on the windshield, just like in the existing road tax system. Each time the vehicle passes the toll booth, the tag will be read and information will be transmitted to the main computer. The tax amount will be either deducted by prepaid or credited by postpaid. "AUTOMATED TOLL COLLECTION SYSTEM USING RFID” [2] in this identification is done with the help of radio frequency. A vehicle will hold an RFID Tag. Reader will be strategically placed at toll plaza. When the vehicle passes the toll naka, the tax amount will be deducted from his prepaid balance.

\section{PROPOSED SYSTEM}

Vehicle arriving at the toll plaza is detected using an IR proximity sensor (capability of sensing upto 11 meters.) and a pulse is generated which is sent to the microcontroller. The microcontroller gives message to computer via an USB TTL module that there is a vehicle present. Computer alerts the HD webcam to take a picture. Webcam in turn sends the captured image to the database. Where the processing, matching and deduction is performed. The Computer sends the notification to microcontroller that it is an authorized vehicle. The microcontroller in turn alerts the motor driver to open the gate and allow the vehicle to pass. Incase if the balance of the vehicle is nil, it blocks it and asks it to join the manual lane which is joint to it and pay there manually. If the vehicle is unauthorized then an alarm will buzz which will alert that it is robbed car and strict actions will be taken. 
Thus the processing becomes faster and no traffic congestion takes place saving money, time, fuel, etc. Leading to the satisfaction the human being.

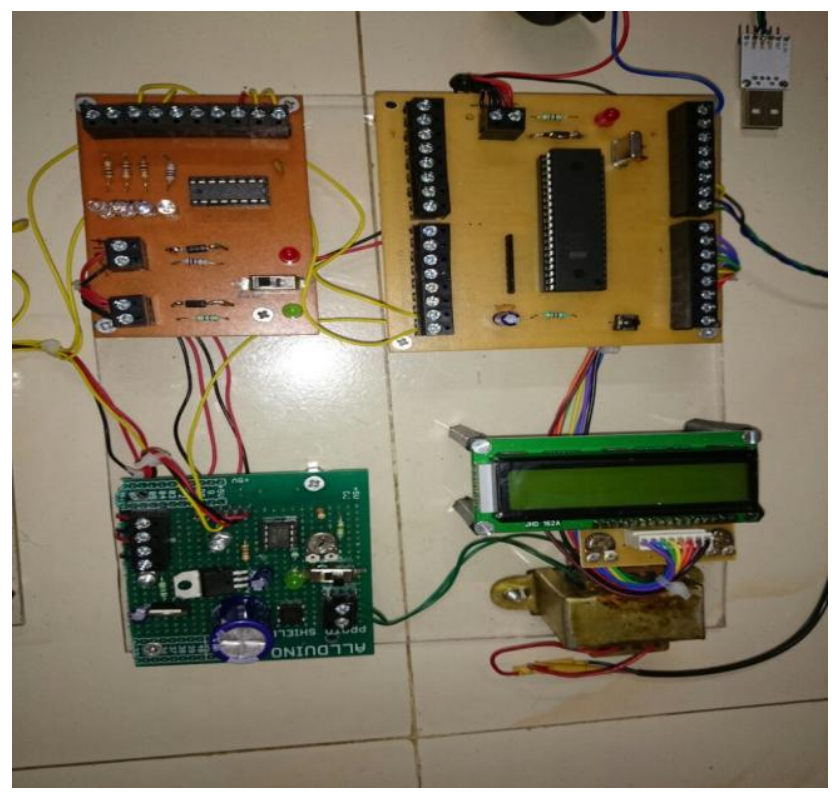

Fig -1: Circuit Diagram.

\subsection{Block Diagram}

\section{PRINTING PHASE:}

\begin{tabular}{|c|c|c|}
\hline $\begin{array}{l}\text { Make entry of the } \\
\text { vehicle in the }\end{array}$ & $\begin{array}{l}\text { Encrypt the } \\
\text { Vehicle no. using }\end{array}$ & $\begin{array}{l}\text { Create an OCR code of } \\
\text { the encrypted data and }\end{array}$ \\
\hline database. & DES algorithm. & Daste it on the vehicle. \\
\hline
\end{tabular}

\section{ACCESS PHASE:}

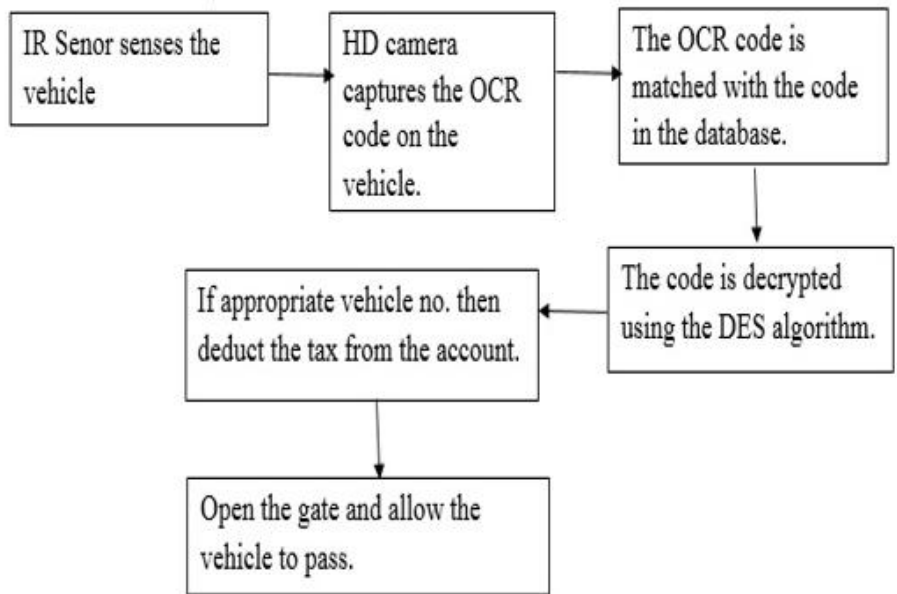

Fig -2: Block Diagram

\subsubsection{Printing Phase}

1. Data of the particular vehicle is filled in the database.

2. Number Plate is encrypted using DES algorithm.

3. An OCR image is created of the encrypted data and it is put on the vehicle.

\subsubsection{Access Phase}

1. When the vehicle arrives on the toll plaza at a particular distance the sensor senses and the digital camera captures the OCR image on the vehicle.

2. The OCR Code is processed using several techniques.

3. Encrypted data on the image is matched with the encrypted data in the database. If matched, the data is decrypted using the same algorithm as used for encryption and the details of the vehicle are identified.

4. If there is sufficient balance then the appropriate amount is deducted from the account. The details of amount deducted and balance are displayed on the screen.

5. Once the balance is deducted, the vehicle is allowed to pass.

6. In case, if the account is nil, then the vehicle is allowed to pass exactly once and the balance will go in minus. On the next journey he/she should pay the appropriate amount in cash immediately. Then only he/she is allowed to pass the toll plaza.

\subsection{Process Flow}

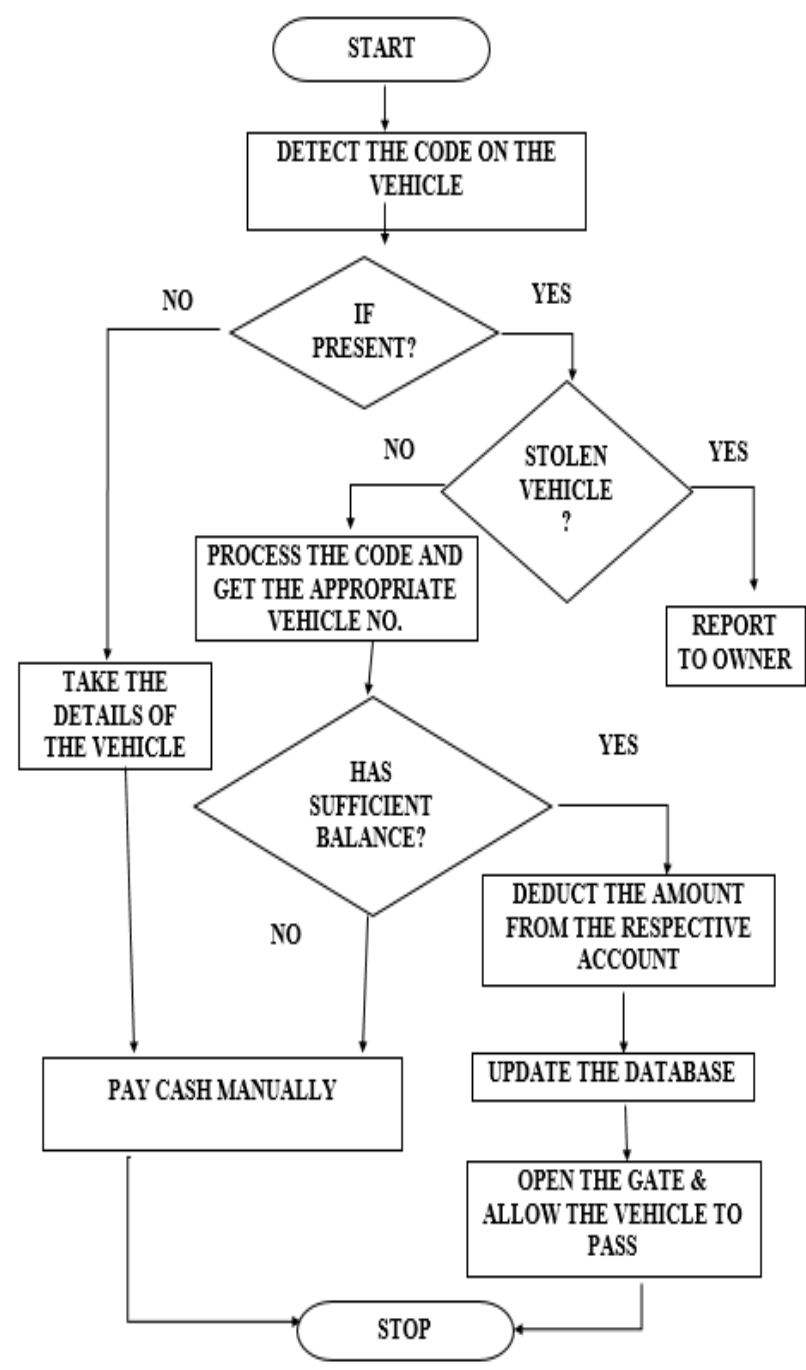

Fig -3: Process Flow 


\subsection{Software}

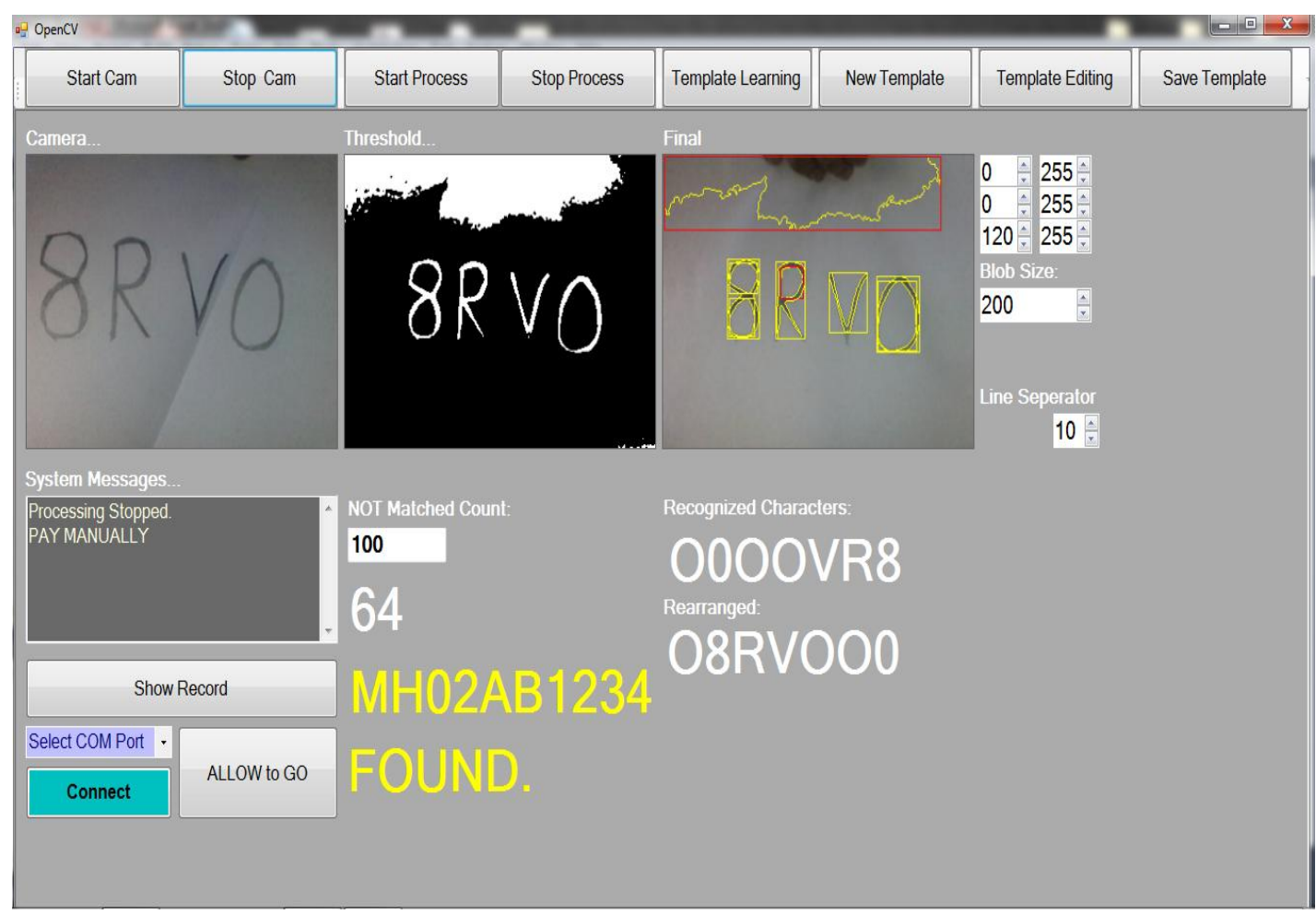

Fig - 4: GUI

As soon as the camera captures the code the processing is done on the code. The code is converted into gray scale and only the letters and alphabets are segregated and each blob is matched with the code in the database. The matching process is done for almost 100 times which is the maximum limit. It is done very fast almost in seconds and the no. at which the match is found is displayed. If found, the respective number of the car is displayed and the appropriate amount is deducted from the account.

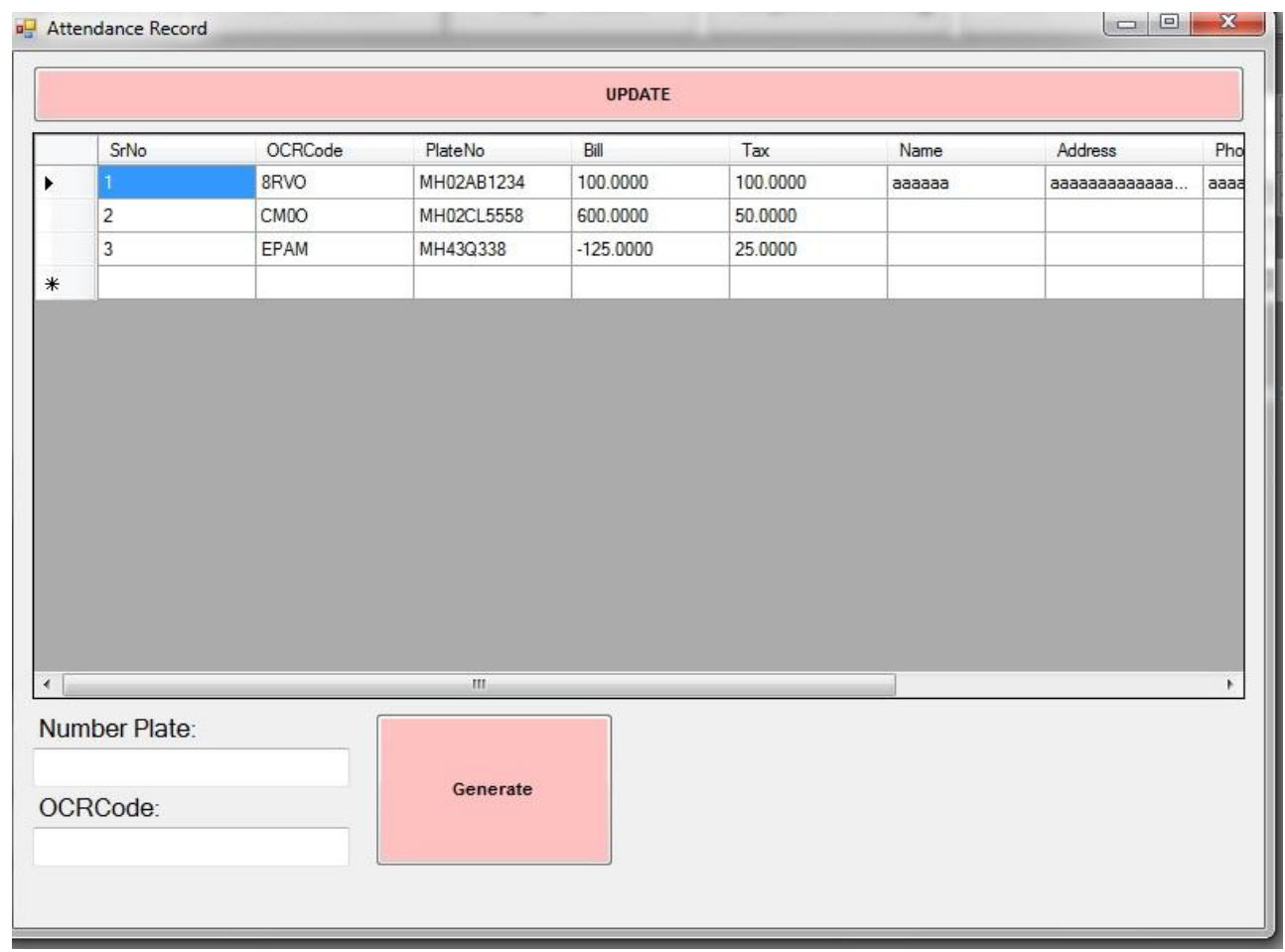

Fig- 5: Database 
In the database a record of each vehicle is kept and an OCR code for a new vehicle is generated by simply entering the vehicle number. Then the entry for respective vehicle is updated in the database. The code is generated using the DES algorithm.

\section{CONCLUSION}

Automatic Toll Collection System using Optical Code Recognition and Encryption uses a simple sticker which is cheap as compared to RFID Tags and avoids the chances of forgery in case of ANPR systems. In addition, it provides security, faster processing, avoids traffic congestion, pollution and is reliable and an efficient toll collection system overcoming the drawbacks of the existing toll collection systems.

\section{ACKNOWLEDGEMENTS}

We take this opportunity to thank our project guide Prof. Swapnil Gharat for offering much-appreciated advice, support and thought-provoking ideas throughout our completion of the project. It is solely his motivation that has driven us in efforts. We are also thankful to all the staff members of the Department of Computer Engineering of Manjara Charitable Trust's Rajiv Gandhi Institute of Technology for their consistent guidance and support.

\section{REFERENCES}

[1] Khadijah Kamarulazizi, Dr.Widad Ismail "Electronic Toll Collection System Using Passive RFID Technology" in Journal of Theoretical and Applied Information Technology.

[2] Pranoti Salunkhe, Poonam Malle, Kirti Datir, Jayshree Dukale, "Automated Toll Collection System Using RFID” in IOSR Volume 9, Issues 2(Jan-Feb 2013).

[3] Kumar Rajeev Ranjan, Abhinav Sinha "Automatic Vehicle Registration System for Tollbooths".

[4] Priyanka Chhoriya, Govinda Paliwal, Poonam Badhan "Image Processing Base Automation Toll Booth In Indian Condition”, April 2013.

[5] Kresimir Romic, Irena Gailc, Alfonzo Baumgartner "Character Recognition Based On Region Pixel Concentration for License Plate Identification". 